\title{
Morpho-Lexical Impact on Resyllabification and Stress Assignment in Suburbanite Jordanian Arabic
}

\author{
Baseel Ali AlBzour ${ }^{1}$ \\ ${ }^{1}$ Department of English Language \& Literature, AABU, Mafraq, Jordan \\ Correspondence: Baseel Ali AlBzour, Assistant professor of Linguistics \& Translation Studies, Department of \\ English Language \& Literature, AABU, 25113, P. O. Box 130207, Mafraq, Jordan. E-mail: \\ nnnbzour@gmail.com
}

Received: July 3, 2015 Accepted: August 4, 2015 Online Published: August 31, 2015

doi:10.5539/ells.v5n3p66 URL: http://dx.doi.org/10.5539/ells.v5n3p66

\begin{abstract}
The present study targets interdisciplinary linguistic effects of morpho-lexical dynamic impacts on phonological processes. Therefore, it succinctly investigates some specific aspects pertaining to two Arabic dialects, namely, Modern Standard Arabic and Suburbanite Northern Jordanian Arabic. The narrow scope of this paper is deliberately confined to fathoming the role of the nominative morpheme marker in the syllable interaction at the word boundary when such a morpheme is in effect. Because both of these dialects abide by the universal ONS-constraint, the deformity of onsetless syllables are sought to be systematically repaired with the least serious constraint violation. On the one hand, the vowel in the syncopated nominative morpheme intervenes in the former, so no epenthesis occurs; on the other hand, the latter employs epenthesis to fix such a problem. This may give deeper insight into answering the question behind MacCarthy's (2007) assumption of the hidden generalizations that rationalize optimal variations in spoken varieties in the Levant. In addition, the researcher believes that the data and the analyses presented in this paper can catalyze curiosity of some researchers to conduct many other relevant works in more depth not only to better explore such a rich interface but also to steer such an analysis towards neurological approaches that advocate parallel distributed processing in an attempt to further attest language acquisition premises in this regard.
\end{abstract}

Keywords: Interdisciplinary, morpho-lexical, enpenthesis, resyllabification, syncopated, constraints, optimality, coda, onset, word-boundary

\section{Introduction}

Jordanian Arabic is a major Levantine variety that does share many linguistic features with other vernacular Arabic dialects. However, there are many major dialects and/or subdialects in Jordan that can be geographically and demographically spotted and traced in various Jordanian provinces and communities (Herzallah, 1990). Suburbanite Northern Jordanian Arabic (henceforth, SNJA) is one of these obviously recognized dialects, mainly spoken in a wide area of northern towns and villages the population of which approximately constitute one third of the total population of the kingdom of Jordan. This does not mean by any means that all SNJA subdialects are exactly the same; rather, these subvarieties share a great deal of linguistic features that qualify them to be distinctively approached under a similar umbrella, especially at the morphological and the phonological levels that segmental phonological analyses cannot fully cater for (Al-Sughayer, 1990).

This paper is primarily expected to shed light on some fundamental aspects of morpho-lexical interaction onmorpho-phonological assumptions and their implementation as well as implications vis-a-vis these Arabic dialects, more specifically whether such dialects diverge due to intrinsic phonological inventories that they possess or as a result of morphological interface that inevitably results in different phonological manifestations regarding assimilation, epenthesis and syncope that all in all govern syllabification and stress assignment in such dialects as such. Segmental and suprasegmental approaches to such dialects can be marginal while trying to fathom the relationship between the underlying forms and the surface representation such as the one conducted by Kenstowicz (1981). This may trigger an explicit motivation to hold some contrastive analysis among some Arabic dialects from a wider optimal perspective when different phonological realizations and behavior substantially surface as a result of lexical and/or morphological circumstances. 
At the phonetic level, Modern Standard Arabic (henceforth, MSA) and all other vernaculars share most consonants and vowels. The disparity at the consonant level is more evident concerning some minute and non-contrastive features among these dialects. The inventory of the vowel and consonant phonemes of both MSA and SNJA is similar to a great extent, yet there are some phonemes that do not fully match. The Phonetic distinction between the voiceless, uvular stop $[\mathbf{q}]$ in these two dialects will be ignored because of its insignificance within the scope of this paper. Studying the description of Arabic inventory, one can see clearly that many sounds are shared with English, yet some other phonemes are peculiar to Arabic as it can be seen in the following chart. What distinguishes these emphatic phonemes, for instance, from their non-emphatic counterparts is the fact that emphatic sounds in Arabic are not simplex sounds; rather they are duplex ones, i.e. they are coronally produced with a secondary articulation involving a retraction of the body of the tongue (Bin-Muqbil, 2006). A rough comparison between Arabic consonants and English can reveal that there exist many similar phonemes, but other contrastive ones do exist as well. This comparison gives the reader an idea about the similarities and the differences of the inventory each language has. First, we have to bear in mind that English /t/ and /d/ are alveolar while Arabic /t/ and /d/ are dental. Second, it is crystal clear that some phonemes are peculiar to Arabic and do not exist in many other languages.

\section{Data and Assumptions}

This begs the following questions: what about the interaction between these phonemes? What about the structuring patterns of these phonemes within the syllable? What about the constraints that govern these syllables and what about the way these syllables do interact with relevance to their morphological environment? Do we have a similar phonological behavior in these languages with rich morphology, i.e. MSA and those with relatively minimal morphological features such as SNJA and even English? The answer can be intuitively negative because of the constraints each system, i.e. phonology or morphology necessitates as such, let alone cases when the two systems overlap.

The data used in this paper, therefore, draws upon specific references to both Standard Arabic and SNJA since the researcher is a native speaker of both, in addition to her advanced mastery of other dialects. A quick review of the current relevant literature has been carried out to investigate the state of affairs of such phonological processes to see if there is any morphological evidence that may trigger such a phenomenon and/ or if there is some more intricate morpho-phonological interface that may best support the analysis of the data within an exclusive generative framework. In the final analysis, this paper is expected to elicit the real motivations that may lead to such apparently huge mismatches and diversity among a myriad of Arabic dialects. This morphophonological interface can be understood in light of the Obligatory Contour Principle (OCP) as explicated by McCarthy (1981) \& (1986) where he mainly argues, "at the melodic level adjacent identical elements are prohibited". Interestingly, this has some significant impact on syllable syllabification/re-syllabification on the one hand as well as stress assignment after all.

The prime concern, therefore, is to examine how morphology in MSA and NSJA interfaces with basic phonological issues regarding syllabification and resyllabification. At the beginning, it would look an easy task, but every day one may realize how diverse and huge and sophisticated the data can be. The researcher has been concentrating on collecting satisfactory data that can clearly support her argument because whenever one reads about Arabic phonology in McCarthy (2000), (2002) and (2007) and Kenstowicz (1983) and (1989) et al, he/she may find how shallow the data are. They have beaten the example 'kataba' i.e. 'he wrote' to death in their analyses (see AlBzour, 2015). Oftentimes, using very limited sources of data may end up with wrong or at least misleading generalizations as it can be clear in the following example presented by Kager and Zonneveld (1999, p. 12) concerning relevant Arabic 'broken' plurals as it can be clearly seen below:

(1)

$\begin{array}{cll}\text { Sg } & \text { Glosses } & \text { PI. } \\ \text { jundub } & \text { 'locust' } & \text { janaadIb } \\ \text { sultaan } & \text { 'sultan' } & \text { salaatIn } \\ \text { xaatam } & \text { 'signet ring' } & \text { xawaatIm }\end{array}$

The problem with their analysis lies in the fact that they posit the assumption that the plural of 'sultaan' is 'salaatIn', similar to 'jundub' and 'janadIb. Accordingly they conclude such templatic structure of Arabic prosody. Unfortunately, all native speakers of Arabic agree that the plural of 'sultaan' is 'salati:n' not 'salaatIn', i.e. the third syllable being stressed instead of the second syllable. This would turn their claims and hypotheses upside down. Hence, the researcher insists in this paper that accurate and ample data should be presented when 
studying any language. Therefore; this researcher is trying to do the following: first, to present as much data as it can be needed; second, to narrow her analysis to the constraints that OT may offer in explaining how syllabification and resyllabification take place in both SNJA and MSA; third, to focus on the data that best show the role of the nominative morpheme at the word-boundary in these two dialects, and how it can impact resyllabification in MSA, then how it leads to an explicit contrast with SNJA, which lacks such case markers; fourth, to explain how such relevant constraints pertaining to CODA and ONSET operate similarly or differently in these two dialects insofar as epenthesis and/or deletion might be accordingly applied.

The first step we need to take and to consider is to extend the comparison beyond the phoneme level into the syllable structure level so that the next argument can be more conspicuous:

(2)

a. Main realizations of English Syllable Structure

\begin{tabular}{llllll}
\hline$\#$ & Type & Example & $\#$ & & \\
\hline 1 & V & A & 9 & CCCVC & Straight \\
2 & VC & Aid & 10 & CCCVCC & Streets \\
3 & CV & Moo & 11 & CCCVCCC & Strengths \\
4 & CVC & Sit & 12 & CCVCC & Treads \\
5 & CCV & Free & 13 & CVCCCC & Texts \\
6 & CVCC & Ships & 14 & CCCV & Stray \\
7 & VCC & Aids & 15 & VCCC & Ants \\
8 & CCVC & Stag & & & \\
\hline
\end{tabular}

\section{b. Arabic Syllable Structure}

Syllable structure in Standard Arabic has been investigated by many scholars such as Al-Ani (1970), Al-Ani and May (1978), McCarthy (1979), Selkirk (1981), Abu-salim (1982), Jarrah (1993) and many others. These scholars tend to concur that such structure in MSA has various underlying inventory that can be manifested in different syllable types since it is a bit more restricted because of the following constraints: (1) No syllable in Standard Arabic can begin with V or CC, so (2) Arabic syllables must begin with a single consonant. Hence, three main syllable patterns in SA can be obviously recognized:

(3)

\section{a. super heavy syllables CVVC \& CVCC.}

b. heavy syllables CVC \& CVV.

\section{c. light syllable: $\mathrm{CV}$.}

\section{Discussion and Analysis}

\subsection{Stress Assignment}

In Arabic, there are three word stress levels: primary, secondary and weak. Arabic stress is predictable; i.e. one can easily determine where stress falls in Arabic words. The following is a summary of Arabic stress rules as summarized by Al-Jarf (2003):

(i) Stress falls on the last super heavy syllable if a word contains one super heavy syllable or more as in the following examples:

(4)

a) /ka-tapt/

I wrote

b) /ki-ta a b/

book

c) /sa-maa-wa at/

skies/heavens

d) Ima-na a-sheer/

saws

e) /taa-wuws/

peacock

f) Ita-saa-beeH/

praises

g) /ta -shaa-ra -kooh/

they shared it 
(ii) Stress falls on the heavy syllable before the final syllable (non-final heavy syllable If a word contains heavy and light syllables, as in the following:

(5)

$\begin{array}{ll}\text { a) Imus-taq-bal/ } & \text { future } \\ \text { b) Imus-ta?-ma-ral } & \text { colony } \\ \text { c) Imas-ta-ral } & \text { ruler } \\ \text { d) IIis-taq-ba-la/ } & \text { received } \\ \text { e) Ifas-sa-ra/ } & \text { interpreted } \\ \text { f) Imuh-sin/ } & \text { good-doer } \\ \text { g) Imu?lim/ } & \text { painful }\end{array}$

(iii) Stress falls on the first syllable if a word contains only light syllables, as in the following:

(6)

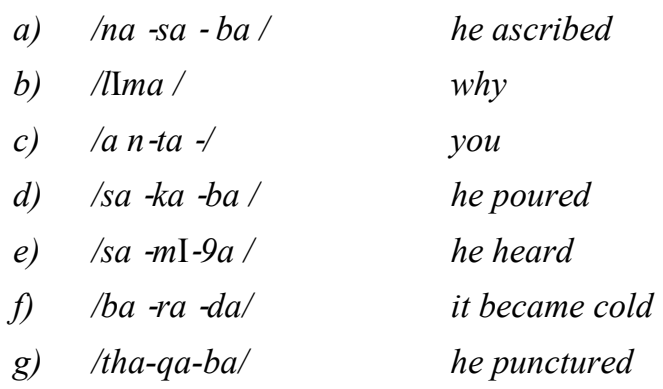

Now, we need to shed light on how the scope of this study can be narrowed down to one aspect of morphophonoly. MSA has four nominal case markers: nominative, accusative, genitive and dative. The researcher is investigating and studying the nominative case marker in MSA as opposed to a null case in SNJA. This nominative marker is a morpheme that should be attached to the end of the noun when it is the subject of a sentence or by default when the noun stands alone or when it is the head of a noun phrase. The phonological form of this morpheme is either [-un] after indefinite common nouns that stand alone in a noun phrase or [-u] when the common noun is definite (Indefiniteness/ definiteness here is confined to the existence/ absence of the definite article [al-] 'the'. There are other types of definiteness, but these are not morphological; they are syntactic and semantic so they are excluded:

\section{MSA}
a. Kitaab-un (a book)
b. al-kItab-u (the book)

\section{SNJA}
a. KItaab (a book)
b. al-kItaab (the book)

These common nouns can occur in compound noun structures which resemble in form and in function the English compounds with a genitive function. The genitive case marker affects the second noun, so it is beyond the scope of interest since we need to concentrate on the nominative morpheme which affects the head noun:

(8)

\section{MSA}
a. KItaab-u al-taalIbI (The student's book)
b. Yawmu al-kItab-I (the book's day)
c. Baytu al-talibI (The student's house)
d. Baabu al-sayyaratI (the car's door)
e. Yawmu al-ummI (mother's day)

\section{SNJA}
a. KItaab al-tallb (The student's book)
b. youm el-kIitaab (the book's day)
c. Bait el-tallb (The student's house)
d. Baab el-sayyara (the car's door)
e. Youm el-ummI (mother's day)

The important issue here is how these common nouns syllabify in isolation in both dialects and how this morpheme in MSA operates lexically at the word boundary and reshapes the syllable structure as opposed to the case in NJA. Consequently, how this resyllabification has a significant impact on the realization of different Arabic dialects to the extent that learners of Arabic may think that these dialects are different languages while 
close scrutiny can evidently reveal that syntactically and semantically they are so similar, but the morphology at the word boundary yields different phonological representations. We need at this level to examine some major principles that constitute the essence of Optimality Theory. These OT constraints can help explain a potential framework that may provide a logical analysis of the various phonological properties in general and of syllable structure in particular. My main goal in the following section is to closely examine such relevant data and then decide whether we can rely on OT to prove or falsify the cross-linguistic implications that Arabic data may yield. Clements and Keyser (1983, p. 28), pinpoint that cross-linguistically the essential set of core syllable types can contain the following sequences: $\mathbf{C V}, \mathbf{V}, \mathbf{C V C}$ AND VC.

\subsection{Syllable Constraints}

Their assumption that leads to such a categorization posits that core syllable types in all languages neither prohibit the existence of onsets nor do they require codas for all their syllables. The most natural one is CV. Therefore, Clements are Keyser (1983) suggest that in order to obtain this CV there can occur two operations that are responsible for producing the other less natural core syllables from this most natural one, i.e. $\mathrm{CV}$. The first option is to delete the initial consonant of the CV syllable type to end up with $\mathrm{V}$. The second operation is to add a final consonant to the CV syllable type to end up with CVC. Thus, we can recognize that there is a markedness process behind this basic syllabification which involves either deletion or insertion based on the set of constraints that are employed in the process of determining the set of possible core syllables that follow what Prince and Smolensky (1993) present as constraints belonging to members of two families: Markedness constraints vs. Faithfulness constraints that do rank differently.

What is practical and feasible about OT is the fact that such constraints have a kind of struggle and conflict among them, so all of them are susceptible to violability, i.e. none of the winning candidates ought to be ideal; rather optimal one is the one that may incur minimal or least serious violations of these constraints the following structural and faithfulness constraints accordingly were proposed by Prince and Smolensky (1993).

\subsubsection{Structural Constraints}

a. NUC: Syllables must have nuclei.

b. *COMPLEX: No more than one $\mathrm{C}$ or $\mathrm{V}$ may associate to any syllable position node.

c. $* \mathbf{M} / \mathbf{V}: \mathrm{V}$ may not associate to margin nodes (onsets and codas).

d. *P/C: C may not associate to peak nodes (nuclei).

e. ONS: Syllables must have onsets.

f. -COD: Syllables must not have codas.

\subsubsection{Faithfulness Constraints}

Such constraints aim at generating a one-to-one correspondence of input segments:

1) PARSE: underlying segments must be parsed into syllable structure.

2) FILL: Syllable positions must be filled with underlying segments.

Prince and Smolensky (ibid), posit that only these two faithfulness constraints, i.e. PARSE and FILL can be comparatively ranked as well as the other two structural ones: ONS and-COD. This sort of ranking reflects a hierarchy or dominance to satisfy the needs of language. However, the other structural constraints, mainly, NUC, ${ }^{*}$ COMPLEX, ${ }^{*} \mathrm{M} / \mathrm{V}$, and $* \mathrm{P} / \mathrm{V}$ are "fixed in superordinate position". Bearing in mind that SA exhibits a tendency to have super heavy syllables CVVC \& CVCC, etc, we can assume that the constraint * COMPLEX is restricted only to the onsets because of the fact that the onset is the only syllable position node that prohibits the 'association of more than one segment', i.e., only one consonant is permissible. On the other hand, there are some syllables with complex nuclei CVV, CVVC, with complex codas CVCC, and with complex nuclei and codas CVVCC.

\section{(9) MSA: CV. CVVC}
a. kItaab
"Book"
b. sIxaam
"Soot"
c. HImaar
"Donkey"
d. ThImaar
"Fruit"
e. Kabeer
"Old" 

f. Sagheer "Young/small"
g. HIbaal "Ropes"
h. rlimaal "Sands"
i. Tubool "Drums"
j. suyool "water floods"

However, SNJA oftentimes shows no restrictions on complex onsets, so CCV, CCVV and CCVVCC are permissible as in (13) as well as CV.CVVC as in (14) where both SA and NJA syllabify similarly:

(10) SNJA CCVVC
a. Ktaab "Book"
b. sxaam "Soot"
c. Hmaar "Donkey"
d. Thmaar "Fruit"
e. Kbeer "Old"
f. Sgheer "Young/small"
g. Hbaal "Ropes"
h. rmaal "Sands"
i. Tbool "Drums"
j. syool "water floods"

(11) MSA \& SNJA CV.CVVC
a. Gharaam "Love"
b. saHaab "Cloud"
c. kamaan "Violin"
d. Zamaan "Time"
e. Pimaad "Proper Noun/Person"
f. Xaraab "Destruction"
g. Shanaar "shame"
h. Paseer "Prisoner"
i. Taweel "Tall/Long"
j. ?aSeer "Juice"

Having these constraints in mind, we need to identify the ranking of these syllable structure constraints in Arabic. We have seen that onsets in both SA and NJA are a must while codas are optional, yet we need also to decide how to rank these structural constraints with relevance to their faithfulness counterparts, i.e. FILL and PARSE, let alone the hierarchy of these two faithfulness constraints with respect to one another, if such dominance would exist. Scrutinizing all these examples that I have presented so far, one can realize that all the syllable types in both dialects have onsets, i.e. onset is mandatory. This proves the assumption that ONS must dominate both, or at least one, of the faithfulness constraints, so we need the following hierarchy at this stage:

\section{(12) ONS >> PARSE, FILL}

This hierarchy of constraints in Arabic proves the hypothesis proposed by Prince and Smolensky (2004, p. 262), which states that 'If ONS dominates either PARSE or FILLII ${ }^{\text {ONS }}$, onsets are required in all syllables of optimal outputs'. However, the data in both SA and NJA show that some syllable types o are open, i.e. the codas are not mandatory as it is the case of onsets. This necessitates the following ranking of-CODA or NOCODA below the other faithfulness constraints: PARSES and FILL:

\section{(13) PARSE, FILL >> NO-CODA}

Accordingly, we can propose thus far the following ranking of both faithfulness and structural constraints: 
(14)

a. ONS $>>*$ Complex $>>$ PARSE, FILL $>>$ NO-CODA

SA

b. ONS $>>>>$ PARSE, FILL $>>$ Complex, NO-CODA

NJA

Now, let us try to apply these constraints as ranked in (18) to see if they yield an optimal choice in both dialects as the data in (15) clearly show:

(15)

\begin{tabular}{lllll}
\hline Sa.Haab & ONS & PARSE & FILL & NOCODA \\
\hline a.SaH.aab & $* !$ & & $* *$ \\
b.Sa. Ha.ab & $* !$ & $* !$ & $*$ \\
c.Sa.Haa.b & & & $*$ \\
d.Sa.Haab & & & $*$ \\
\hline
\end{tabular}

Now, compare the divergence between MSA and SNJA as the data in (9) and (10) can reveal because of *COMPEX in MSA as opposed to SNJA since *COMPEX stipulates that syllables must have one consonant at edge according to Archangeli and Langendoen (1997); accordingly, it dominates other constraints in MSA except ONS so the optimal choice is different, i.e. [Hmaar] in SNJA and [Himaar] in MSA.

(16) SNJA

\begin{tabular}{|c|c|c|c|c|c|}
\hline Hmaar & ONS & PARSE & FILL & COMPLEX & NOCODA \\
\hline a. HIm.aar & $* !$ & & $*$ & & $* *$ \\
\hline b.HI.maar & & & $*$ & & $*$ \\
\hline c.HI.maa.r & & $* !$ & * & & $*$ \\
\hline d. Hmaar & & & & * & $*$ \\
\hline
\end{tabular}

(17) SA

\begin{tabular}{|c|c|c|c|c|c|}
\hline Hmaar & ONS & *COMPLEX-ONS & PARSE & FILL & NO-CODA \\
\hline a. HIm.aar & $* !$ & & & $*$ & $* *$ \\
\hline b. HI.maar & & & & $*$ & $*$ \\
\hline HI.maa.r & & & & * & * \\
\hline Hmaar & & $!^{*}$ & & & * \\
\hline
\end{tabular}

The analysis so far shows how these two dialects are different from in some aspects and similar in some other aspects to some other Arabic dialects such as Moroccan where multiple onsets and onsetless syllables are fairly possible, (Mascaro, 2004, p. 516). However, a need arises at this stage of analysis to determine whether the faithfulness constraints FILL and PARSE have a specific ranking or not because we need to know how onsetless syllables can be satisfied. Do they undergo a process of epenthesis or a process of deletion? Arabic tends to satisfy this optimal structure by applying epenthesis rather than deletion, so an epenthetic glottal stop [1] is inserted whenever such a need may arise. This means that FILL must be ranked below PARSE since the former is admissibly violable as MacCarthy (1979) explicates concerning some Arabic Binyanim. Consider the following data:

(18)

$\begin{array}{lll}\text { SA } & \text { NJA } & \text { Glosses } \\ \text { a. Axbaar } & \text { axbaar } & \text { "News" } \\ \text { b. asraar } & \text { asraar } & \text { "Secrets" } \\ \text { c. ahraam } & \text { ahraam } & \text { "Pyramids" } \\ \text { d. amaan } & \text { amaal } & \text { "safety" } \\ \text { e. ameer } & \text { ameer } & \text { "Prince" } \\ \text { f. Israaf } & \text { Israaf } & \text { "Extravagnce" } \\ \text { g. Ishraaf } & \text { Ishraaf } & \text { "supervision" } \\ \text { h. asnaan } & \text { Isnaan } & \text { "Teeth" } \\ \text { i. IHtifaal } & \text { IhtIfaal } & \text { "Celebration" } \\ \text { j. Ihmaal } & \text { Ihmaal } & \text { "Carelessness" }\end{array}$


The data in (18) show how both SA and NJA have words that start with an initial vowel. To overcome this problem, an optimal candidate must meet the ONS constraint. Therefore, either syncope or epenthesis would solve the problem. However, both dialects seem to prefer the latter choice, so an epenthetic glottal stop [?] is inserted initially to the first syllable of these wors; thus we end up with the following: (i.Panta/ ?inta, ii.?ahmad/PiHmad, iii.?akal, iv. ?amal, v. ?ameer, vi.?israaf, vii. ?ishraaf, viii. ?asnaan/ Pisnaan, ix. PIhtifaal and x.Puktub). Thus the following ranking may be proposed at this final stage in this regard to show that PARSE is higher than FILL in both dialects:

\section{(19) MSA: ONS, *COMPLEX $>>$ PARSE $>>$ FILL $>>$ NO--CODA}

\section{(20) SNJA: ONS, >>PARSE $>>$ FILL $>>$ NO-CODA, COMPLEX}

So far, we have examined these data at the simple word level in both dialects. Now, we need to closely examine how the nominative case marker [-u]/ [un] and the absence of such marking morpheme differently affect the syllabification in both dialects. Let us examine the same words in (18) when used in the nominative case where an explicit morpheme is used in MSA while a null case morpheme marker is implicitly understood in SNJA.

\begin{tabular}{|c|c|c|}
\hline a. axbaar-un & axbaar & "News" \\
\hline asraar-un & asraar & "Secrets" \\
\hline ahraam-un & ahraam & "Pyramids" \\
\hline amaan-un & amaan & "safety" \\
\hline ameer-un & ameer & "Prince" \\
\hline Israaf-un & Israaf & "Extravagnce" \\
\hline Ishraaf-un & Ishraaf & "supervision" \\
\hline asnaan-un & Isnaan & "Teeth" \\
\hline i. IHtIfaal-un & IHtIfaal & "Celebration" \\
\hline j. Ihmaal-un & Ihmaal & "Carelessness" \\
\hline
\end{tabular}

The coda of the second syllable resyllabfies and takes the onset position of the next syllable. At this level, a new constraint is needed to interact with other constraints in MSA. This constraint is ALIGN-R, which stipulates that root morpheme boundaries must be aligned with syllable boundaries at both edges. This constraint would compete with the ONS constraint, and the latter dominates. In addition to epenthesis word-initially, resyllabification is a repair strategy that Arabic resorts to when an onsetless syllable emerges at word-boundaries

(22) ONS >>ALIGH (R)

\begin{tabular}{lll}
\hline asnaan+un & ONS & ALIGH (R) \\
\hline $\begin{array}{l}\text { a. } \text { Pas.nan.un } \\
\text { c. } \text {. } \text { as.na.na.nun }\end{array}$ & $* !$ & $*$ \\
\hline
\end{tabular}

Furthermore, the genitive compounding construction in SA yields another basic difference between the two dialects. Hence, another constraint needs to be examined, namely ALIGN (W), which according to Harris and Gussmann (2003) states that the right edge of a word must be aligned with the right edge of a syllable. Examine the data in (23) and (24) to see how both dialects yield different outputs:

\section{(23) MSA}

$$
\begin{array}{ll}
\text { a. } & \text { axbaar + un + al-Harb } \\
\text { b. } & \text { asraar + un + al+ Hayaat } \\
\text { c. } & \text { ahraam + un + al + faraa? Ina } \\
\text { d. } & \text { amaan + un + al+ mustaQbal } \\
\text { e. } & \text { ameer + un + al + Harb } \\
\text { f. Israaf + un +al + naas } \\
\text { g. Ishraaf + un + al+ mudeer }
\end{array}
$$

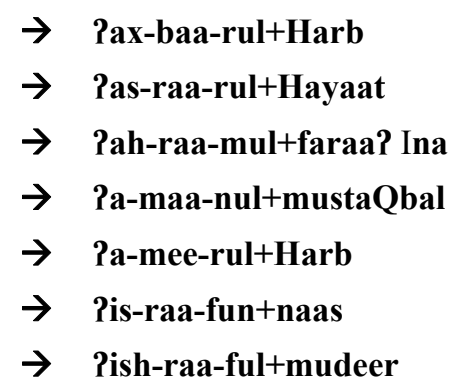

\author{
"War's News" \\ "Life's Secrets" \\ "Pharaohs' Pyramids" \\ "future's safety" \\ "War's Prince" \\ "People's Extravagnce" \\ "Director's supervision"
}




$$
\begin{array}{ll}
\text { h. } & \text { asnaan }+ \text { un }+ \text { al+ mIsht } \\
\text { i. } & \text { IHtIfaal + un + al+ nas } \\
\text { j. } & \text { Ihmaal + un + al + Tallb }
\end{array}
$$

\section{(24) SNJA}

$$
\begin{array}{ll}
\text { a. } & \text { Axbaar + al-Harb } \\
\text { b. } & \text { Asraar + al + Hayaat } \\
\text { c. } & \text { ahraam + al + faraa? Ina } \\
\text { d. } & \text { amaan + al + mustaQbal } \\
\text { e. } & \text { ameer + al + Harb } \\
\text { f. } & \text { Israaf + al + naas } \\
\text { g. } & \text { Ishraaf + al + mudeer } \\
\text { h. } & \text { asnaan + al + mIsht } \\
\text { i. } & \text { IHtIfaa + al + nas } \\
\text { j. } & \text { Ihmaal + al + Tallb }
\end{array}
$$

\author{
“Comb's Teeth" \\ "People's Celebration" \\ "Student's Carelessness"
}

$\begin{array}{ll}\rightarrow & \text { Pax-baa-rill+Harb } \\ \rightarrow & \text { Pas-raa-rill+Hayaat } \\ \rightarrow & \text { Pah-raa-mIl+faraa? Ina } \\ \rightarrow & \text { Pa-maa-nIl+mustaQbal } \\ \rightarrow & \text { Pa-mee-rill+Harb } \\ \rightarrow & \text { PIs-raa-fIn+naas } \\ \rightarrow & \text { PIsh-raa-fIl+mudeer } \\ \rightarrow & \text { Pas-naa-nIl+misht } \\ \rightarrow & \text { PIH-tI-faa-IIn+nas } \\ \rightarrow & \text { PIh-maa-IIt+TalIb }\end{array}$

"War's News"
"Life's Secrets"
"Pharaohs' Pyramids"
"future's safety"
"War's Prince"
"People's Extravagnce"
"Director's supervision"
"Comb's Teeth"
"People's Celebration"
"Student's Carelessness"

As we can notice, ONS dominates both ALIGN (R) and ALIGN (W) in SA, and so does it in SNJA as it can be seen in (25) and (26) below. However, SA tends to drop the consonant of the nominative morpheme in genitive compounding and retain the vowel segment. This vowel solves a problem since it serves as the nucleus of a new emerging syllable which is a result of the coda of the previous syllable-functioning as a new onset- and the coda of the following syllable /al/ which lost its onset vowel.

(25)

\begin{tabular}{lllll}
\hline asnaan+un\#al+mIsht & ONS & ALIGH (R) & PARSE & FILL \\
\hline a. as.nan.un.al.mIsht & $* ! * ! * !$ & & & \\
G. b. Pas.na.nul.mIsht & & $* *$ & $*$ & $*$ \\
c. as.na.nu.al.mIsht & $* !$ & $*$ & $*$ & $*$ \\
\hline
\end{tabular}

On the other hand, SNJA behaves a bit differently than SA though the optimal objective is similar, i.e. generating an onsetful syllable at the word boundary via epenthesis instead of resyllabification:

(26)

\begin{tabular}{llll}
\hline asnaan\#al+mIsht & ONS & ALIGH (R) & PARSE \\
\hline a. as.nan.al.misht & $* ! * !$ & & FILL \\
c. Pas.na.nu.n.m.mIsht & $* *$ & $*$ & $* *$ \\
\hline
\end{tabular}

\section{Conclusion}

In conclusion, this paper has aimed at investigating some aspects pertaining to lexical interference and its role in morpho-phonological interface and such relevant impacts on two Arabic dialects, namely, MSA and SNJA. The scope of this paper is clearly confined to elucidating the role of the MSA nominative morpheme marker in shaping the syllable interaction at the word boundary. Because both dialects go in conformity with the somewhat universal ONS constraint, they tend to repair the deformity of onsetless syllables. SNJA employs epenthesis to fix the problem while MSA vowel in the syncopated nominative morpheme intervenes, so no epenthesis occurs. In fact, this is just one significant aspect of the problem, and the researcher believes that the data in this paper can ignite curiosity of some researchers to conduct many other relevant works in more depth to better explore such a rich interface. This may give deeper insight into answering the question behind MacCarthy's (2007) assumption of the hidden generalizations behind the fact that spoken varieties in the Levant, i.e. Syria, Lebanon, Palestine-while he skipped Jordan-"typically have complex opaque interactions among vowel epenthesis, stress assignment and syncope.

\section{References}

Abu-Salim, I. M. (1982). A reanalysis of some aspects of Arabic phonology: A metrical approach. Unpublished Ph.D. dissertation. Urbana, IL: University of Illinois. 
AlBzour, N. (2015). Syllable structure in Rumthawi Arabic. Advances in Language and Literary Studies, 6(4), 185-194.

Al-Sughayer, K. I. (1990). Aspects of comparative Jordanian and modern standard Arabic phonology. Unpublished Ph.D dissertation. Michigan: Michigan State University.

Archangeli, D., \& Langendoen, D. T. (1997). Optimality theory: An overview. Blackwell Publishers.

Bin-Muqbil, M. S. (2006). Phonetic and phonological aspects of Arabic emphatics and gutturals. Unpublished Ph.D dissertation. Madison: University of Wisconsin, Madison.

Clements, G. N., \& Keyser, S. J. (1983). CV phonology: A generative theory of the syllable. Cambridge, Mass.: MIT Press.

Harris, J., \& Gussman, E. (2003). Word-final onsets. Rutgers Optimality Archive, 575.

Herzallah, R. S. (1990). Aspects of Palestinian Arabic phonology: A nonlinear approach. Unpublished Ph.D. dissertation. Cornell University.

Kager, R. (1999). Optimality theory. Cambridge: Cambridge University Press. http://dx.doi.org/10.1017/CBO9780511812408

Kager, R., \& Zonneveld, W. (1999). (Eds.). The prosody-morphology interface. Cambridge: Cambridge University Press.

Kenstowicz, M. (1981). Vowel harmony in Palestinian Arabic: A suprasegmental analysis. Linguistics, 19(5/6), 449-466. http://dx.doi.org/10.1515/ling.1981.19.5-6.449

Kenstowicz, M. (1983). Parametric variation and accent in the Arabic dialects. CLS, 19, 205-213.

Kenstowicz, M. (1999). Phonology in generative grammar. Cambridge: Blackwell Cambridge \& Oxford, UK.

Kiprasky, P. (2003). Syllables and moras in Arabic. In C. Fery \& R. Van De Vijver (Eds.), The syllable in optimality theory (pp. 147-183). Cambridge: Cambridge University Press. http://dx.doi.org/10.1017/CBO9780511497926.007

Mascaro, J. (2004). Eternal allomorphy as emergence of the unmarked. In J. McCarthy (Ed.), Optimality theory in phonology (pp. 513-522). http://dx.doi.org/10.1002/9780470756171.ch28

McCarthy, J. (1979). On stress and syllabification. Linguistic Inquiry, 10, 443-465.

McCarthy, J. (1981). A prosodic theory of nonconcatinative morphology. Linguistic Inquiry, 12, 373-413.

McCarthy, J. (1986). OCP effects: Gemination and anti-gemination. Linguistic Inquiry, 17, 207-263.

McCarthy, J. (2002). A thematic guide to optimality theory. Cambridge: Cambridge University Press.

McCarthy, J. (2007). Hidden generalizations: Phonological opacity in optimality theory. Equinox Publishing.

Prince, A., \& Smolensky, P. (1993). Optimality theory: constraint interaction in generative grammar. RUCCS-TR-2. Rutgers Optimality Archive-537.

Prince, A., \& Smolensky, P. (2004). Optimality theory: Constraint interaction in generative grammar. Blackwell: Malden, MA; Oxford, UK. http://dx.doi.org/10.1002/9780470759400

Selkirk, E. (1984). Phonology and syntax: the relation between sound and structure. Cambridge, Mass: MIT Press.

Vaux, B., \& Nevins, A. (2008). (Eds.). Rules, constraints and phonological phenomenon. Oxford: Oxford University Press.

\section{Copyrights}

Copyright for this article is retained by the author(s), with first publication rights granted to the journal.

This is an open-access article distributed under the terms and conditions of the Creative Commons Attribution license (http://creativecommons.org/licenses/by/3.0/). 